\title{
The changing nature of hydroclimatic risks across South Africa
}

\author{
Adam Schlosser ${ }^{1} \cdot$ Andrei Sokolov $^{1} \cdot$ Ken Strzepek $^{1} \cdot$ Tim Thomas $^{2} \cdot$ Xiang Gao $^{1}$. \\ Channing Arndt ${ }^{2}$
}

Received: 20 August 2020 / Accepted: 24 September 2021 / Published online: 27 October 2021

(c) The Author(s) 2021

\begin{abstract}
We present results from large ensembles of projected twenty-first century changes in seasonal precipitation and near-surface air temperature for the nation of South Africa. These ensembles are a result of combining Monte Carlo projections from a human-Earth system model of intermediate complexity with pattern-scaled responses from climate models of the Coupled Model Intercomparison Project Phase 5 (CMIP5). These future ensemble scenarios consider a range of global actions to abate emissions through the twenty-first century. We evaluate distributions of surface-air temperature and precipitation change over three sub-national regions: western, central, and eastern South Africa. In all regions, we find that without any emissions or climate targets in place, there is a greater than $50 \%$ likelihood that mid-century temperatures will increase threefold over the current climate's twostandard deviation range of variability. However, scenarios that consider more aggressive climate targets all but eliminate the risk of these salient temperature increases. A preponderance of risk toward decreased precipitation ( 3 to 4 times higher than increased) exists for western and central South Africa. Strong climate targets abate evolving regional hydroclimatic risks. Under a target to limit global climate warming to $1.5^{\circ} \mathrm{C}$ by 2100 , the risk of precipitation changes within South Africa toward the end of this century (2065-2074) is commensurate to the risk during the 2030s without any global climate target. Thus, these regional hydroclimate risks over South Africa could be delayed by 30 years and, in doing so, provide invaluable lead-time for national efforts to prepare, fortify, and/or adapt.
\end{abstract}

Keywords Climate change $\cdot$ Risk $\cdot$ Precipitation $\cdot$ Temperature $\cdot$ Mitigation

\section{Introduction}

Evidence is mounting that Africa's climate is changing and that these trends will continue through the twenty-first century (e.g., Niang et al. 2014). Current efforts to provide more spatially refined climate change information over Africa are ongoing (e.g., Lennard

Adam Schlosser

casch@mit.edu

Joint Program On the Science and Policy of Global Change, MIT, Cambridge, MA, USA

2 International Food Policy Research Institute (IFPRI), Washington, DC, USA 
et al. 2018). Yet, these efforts require computationally expensive regional climate models with high spatial resolution to be exercised, and thus limit a comprehensive and coordinated sampling of simulations across structural uncertainties in both the regional and global climate-model responses. As a result, a range of outcomes in climate-change projections derived from individual assessments exist, and studies performed with a small sample size of model simulations lack a complete distribution of outcomes (e.g., Crétat et al. 2012). Therefore, there remains a distinct need for efficient methods that provide comprehensive samples of all the plausible model solutions to future human-forced climate change. Furthermore, these large-ensemble simulations should also have the ability to consider a number of different scenarios that consider a range of global emissions pathways and/or climate targets, and provide spatial details that are commensurate to the needs of regional impact studies. In this study, we analyze the likelihood of changes in precipitation and surface-air temperature in the coming decades and into the latter half of this century for the greater southern Africa region with a regional emphasis over South Africa. We employ a technique (Schlosser et al. 2012) that constructs large ensembles of plausible climate change. This method combines plausible patterns of human-forced regional climate change with a comprehensive assessment of the global climate change response as determined by the MIT Integrated Global System Model (Reilly et al. 2018). We evaluate the resultant distributions over three selected regions over South Africa that correspond with notable climatic features. We identify the salient shifts in these derived distributions from a reference emission scenario to moderate to aggressive climate-stabilization policies. We close with summary remarks and discussion of ongoing work and applications.

\section{Assessment of regional climate shifts}

\subsection{Region of study and variables of interest}

The overall area of study (Fig. 1) is an extension and complement to prior work (Arndt et al. 2019; Schlosser and Strzepek 2015; and Fant et al. 2015) that provides multi-sector socio-economic-environmental assessments of climate risks for developing nations across Africa, and the effectiveness of low-carbon pathways to reduce risks. This study will present a screening-level assessment of potential climate shifts over southern Africa and focus on two key hydro-climatic variables: precipitation and near-surface air temperature $\left(T_{a}\right)$. In subsequent work, these results will be used as inputs for assessments of climate change impacts to agriculture yields (Thomas et al. 2020, forthcoming) within South Africa. In this vein, we focus on three sub-regions across South Africa (denoted in Fig. 1) and provide a more quantitative analysis of climate risk and the impact of low-carbon pathways across three decadal epochs (2030s, 2050s, and 2065-2075). A description of the model experimentation and methodology is provided in the next section. Below, we describe some of the distinct seasonal features of $T_{a}$ and precipitation of the current climate that are aligned and distinguish our three regional areas of focus: eastern, central, and western South Africa (ESoAfr, CSoAfr, and WSoAfr, respectively). Our historical assessment is based on the observations taken from the Global Precipitation Climatology Project (GPCP, Huffman et al. 2009, and updates by Adler et al. 2018) as well as $T_{a}$ from the Climate Research Unit (CRU, e.g., Osborn and Jones 2014).

Among the three regions considered, the western South Africa (WSoAfr) region is primarily distinguished by the persistently lowest rates of precipitation across all seasons 

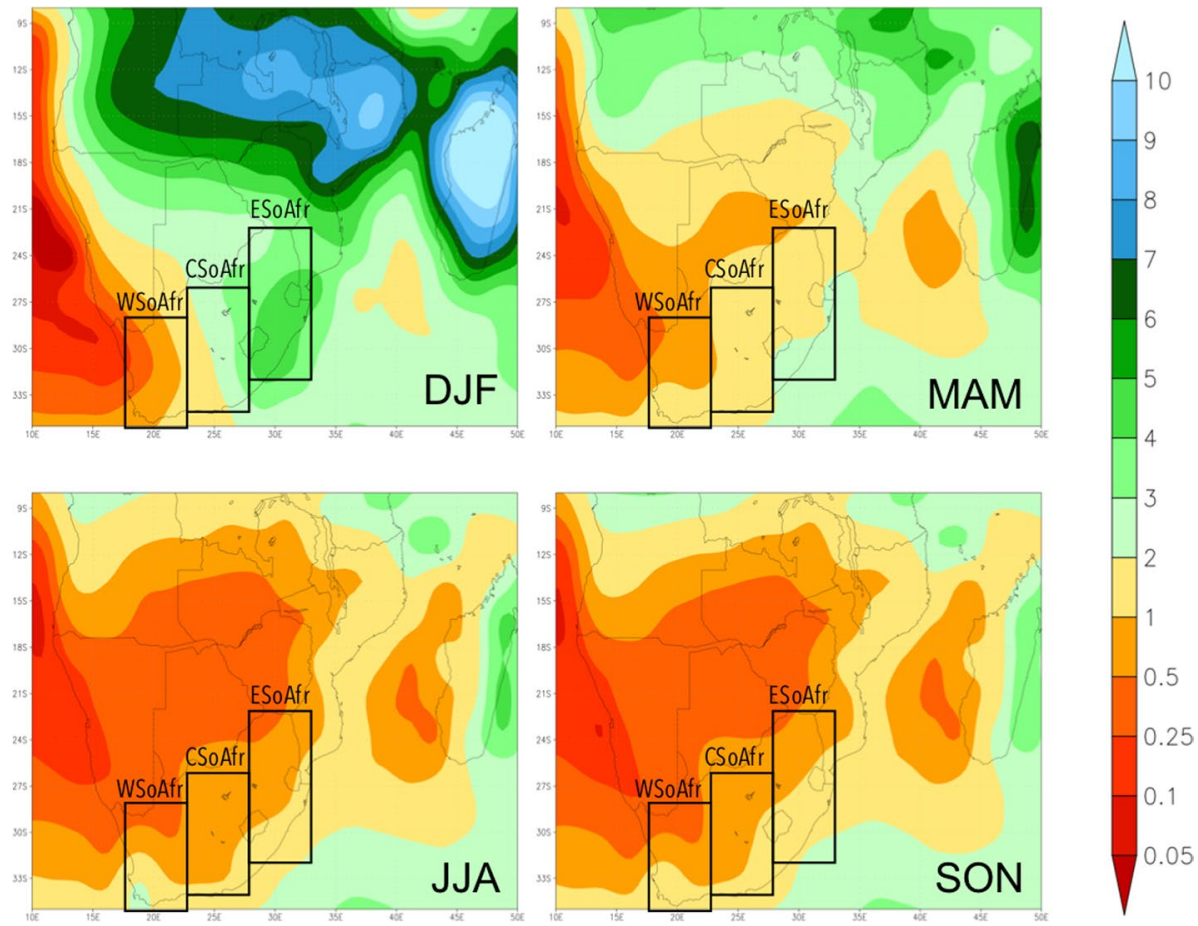

Fig. 1 Seasonal averaged maps (1979-2009) of precipitation (mm/day) for northern Africa. Results are shown for December-February (DJF); March-May (MAM); June-August (JJA); and September-November (SON). Results are based on the data from the Global Precipitation Climatology Project (GPCP, Huffman et al., 2007)

(Fig. 1 and Table 1). This also results in the weakest amplitude in the seasonal cycle of precipitation. Furthermore, due to the localized precipitation maxima over the Cape Town area during JJA, the seasonal cycle of precipitation averaged over the WSoAfr region is opposite in phase to the CSoAfr and ESoAfr regions. In contrast, the ESoAfr region experiences the highest precipitation rates during the summer (DJF) season, and the transition

Table 1 Mean (bold) and standard deviations (italics) of area-averaged precipitation and surface-air temperature for the western, central, and eastern South Africa regions (WSoAfr, CSoAfr, and ESoAfr respectively) of study. Results are presented for two seasonal mean periods: December-February (DJF) and June-August (JJA). The diagnostics of precipitation (units in mm/decads, decad $=10$ days) are based on the Global Precipitation Climatology Project (units in ${ }^{\circ} \mathrm{C}$ ), and surface-air temperature is based on observations assembled by the Climate Research Unit (CRU). See text for citations to data. Statistics span the years 1979-2019, and note that the standard deviation estimates are based across decadal means for each season so as to serve as a baseline for the decadal mean changes assessed in the twenty-first century scenario projections

\begin{tabular}{llrrr}
\hline & & \multicolumn{1}{c}{ WSoAfr } & \multicolumn{1}{c}{ CSoAfr } & \multicolumn{1}{c}{ ESoAfr } \\
\hline Precipitation & DJF & $\mathbf{7 . 3} \pm 0.5$ & $\mathbf{2 3 . 3} \pm 1.5$ & $\mathbf{3 9 . 5} \pm 1.7$ \\
& JJA & $\mathbf{1 0 . 2} \pm 0.5$ & $\mathbf{4 . 7} \pm 1.0$ & $\mathbf{5 . 2} \pm 0.7$ \\
Temperature & DJF & $\mathbf{2 3 . 5} \pm 0.3$ & $\mathbf{2 3 . 0} \pm 0.3$ & $\mathbf{2 2 . 7} \pm 0.2$ \\
& JJA & $\mathbf{1 1 . 9} \pm 0.3$ & $\mathbf{1 1 . 1} \pm 0.3$ & $\mathbf{1 3 . 9} \pm 0.3$ \\
\hline
\end{tabular}


to the wet season is abrupt as the landscape of spring season (SON) precipitation is very similar to the winter (JJA). Given these strong contrasts between the western and eastern flanks of South Africa, the CSoAfr region represents a distinct transition region, with a seasonal cycle that is in phase with but an amplitude that is almost half that of ESoAfr. The seasonality of $T_{a}$ exhibits more consistency across these regions compared to precipitation (Fig. 2 and Table 1). The area-averaged seasonal cycles are all in phase and comparable in terms of magnitude. A notable distinction is that ESoAfr experiences the warmest temperatures during the winter season (JJA), yet it contains the largest area of coolest temperatures (along its inland western flank) as well as the location of the coolest temperature for the region. However, this is more than offset by the warmest temperatures along its coastal boundary. In contrast, the WSoAfr and CSoAfr regions do not experience as strong a contrast in surface-air temperatures.

In order to gauge a degree of salience to the changes produced by the ensemble scenarios of change (described in the next sections), we have also assessed the interdecadal standard deviation of the seasonal, area-averaged quantities (Table 1, in italics). For surface-air temperature, the standard deviations are very consistent across seasons and the regions. For precipitation, the highest variabilities follow the region and season of highest mean (CSoAfr and ESoAfr during DJF). In our assessment of the distribution of changes across the twenty-first century (Sect. 2.4), we will highlight the portions of the distributions that are in exceedance to these variance statistics and, in this way, represent the risk of salient change. It should be noted that the limited temporal extent of these historical datasets may introduce a sensitivity to the variance statistics.

\subsection{Scenarios of global change}

The set of scenarios for this study was selected from the 2018 Food, Energy, Water, and Climate Outlook produced by the MIT Joint Program on the Science and Policy of Global Change using the Integrated Global System Model (IGSM, Reilly et al. 2018). Each IGSM scenario consists of a large ensemble of 400 members. The ensemble provides a multidimensional Latin-Hypercube sampling that spans the plausible Earth systems' response to natural and anthropogenic drivers, with the sampling boundaries determined by observations (e.g. Sokolov et al. 2018 and Libardoni et al. 2018). It also spans a range of global emissions policies and is based on a regionally detailed, multi-sector, economy-wide model that includes pricing of fossil fuels, fossil resources, and vintage capital in capital-intensive sectors (e.g., Chen et al. 2016). Under the policy scenarios that are described below, prematurely retired capital stock and the need to replace conventional energy sources with more expensive, low-carbon options draw investment resources away from other sectors of the economy and, thus, have an impact on GDP growth in mitigation scenarios. However, it is reallocated toward those energy sources that meet the emissions reduction targets at least cost.

Four scenarios, developed to span a range of possible global actions to abate greenhouse gas emissions over the coming century, were used to explore climate-change risks.

Reference (REF) This scenario has no explicit climate mitigation policies anywhere in the world. Thus, it represents a world in which there is no Paris Agreement and no alternative action towards reducing emissions for the sake of limiting climate change. However, it includes some energy policies such as fuel economy standards, renewable electricity requirements, and the gradual phase-out of old coal power plants that are presently 


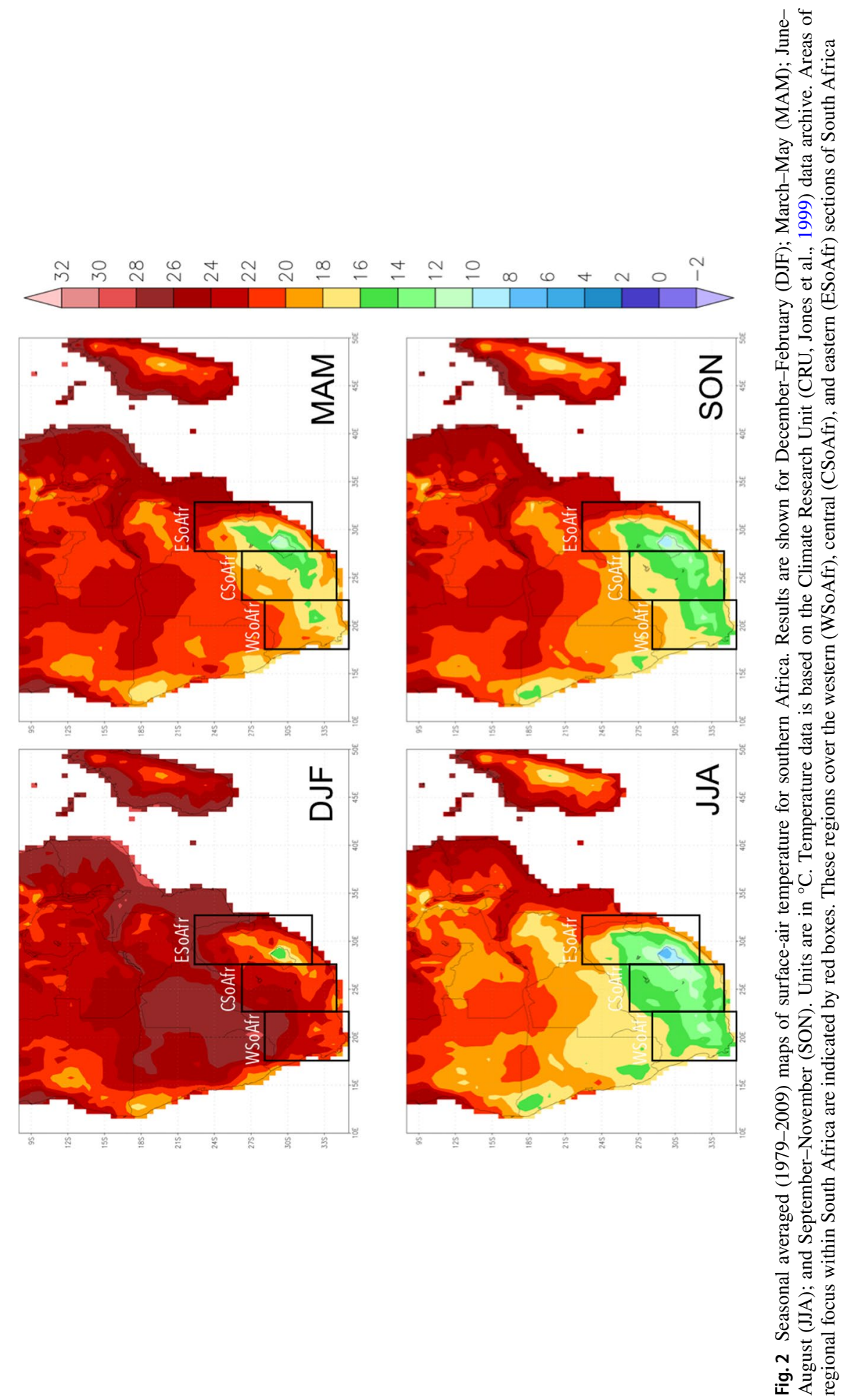


occurring with various motivations. These motivations include reducing imported oil dependence, using less of exhaustible resources, or to reducing conventional pollutants. Such efforts may in part reflect concerns about climate change, but the policies have no specific greenhouse gas emissions targets. The REF serves as a baseline scenario because of its simplicity. Metrics from the other scenarios are often presented as the difference between another scenario and the REF scenario. It provides the upper assessment of our modeled physical risks.

Paris Forever (PF) Countries meet the mitigation targets in their Nationally Determined Contributions (NDCs) and continue to abide by them through the end of the century. The Paris Agreement includes NDCs submitted at the 2015 Paris Conference of the Parties (COP) of the Framework Convention on Climate Change (FCCC). These NDCs-aimed at the reduction of $\mathrm{CO}_{2}$ and other GHG emissions-generally deepened and extended through 2030 those made at the 2009 Copenhagen COP through 2020. These reductions are typically expressed as (1) an absolute emissions target (ABS), measured as an annual level of emissions measured in Mt; (2) a percentage reduction from a pre-determined baseline, which can easily be converted into an absolute emissions target; or (3) an emissions intensity target (INT), measured as emissions in relation to GDP.

2C This scenario aims to limit climate warming to no higher than a $2{ }^{\circ} \mathrm{C}$ global average at 2100 . This is achieved by implementing a globally coordinated, smoothly rising carbon price-such that emissions are reduced. Variations in mitigation policies result in the overall uncertainty of different patterns of resource and energy use, different choices of technology, and drag on overall economic growth. This is also combined with the uncertainty of the global climate response that is represented in the MIT Earth System Model (MESM, Sokolov et al. 2018). As described in Reilly et al. (2018), these co-evolving uncertainties projected within a Latin-hypercube sampling results in an overall probability of achieving the target at $66 \%$.

15C Similar to the $2 \mathrm{C}$, this scenario aims to limit climate warming to no higher than $1.5{ }^{\circ} \mathrm{C}$ global average at 2100 . Under the similar Latin-hypercube sampling of structural uncertainties within the Earth and human model systems, this results in a $50 \%$ probability of achieving the climate target (i.e., 200 of the 400-member ensemble meet the target).

These scenarios result in distinct distributions of global averaged changes in key climate variables (Fig. 3, shown are results for decadal mean changes in the 2050s). The mid-century impact of the more aggressive climate-based targets (i.e., $15 \mathrm{C}$ and $2 \mathrm{C}$ scenarios) is distinguished by the majority of their distribution of outcomes falling outside the distribution of the REF scenario. In addition, shifts in the modal value of change and the percentage of the distribution at the modal value, as well as the total range of outcomes (i.e., width of the distribution), highlight the notable impact of the aggressive climate targets at reducing (and eliminating) the risk of strongest changes. The PF scenario, which captures the current global commitments to reduce emissions (under the Paris Agreement), shows a discernible shift toward lower risks of change, yet considerable overlaps (particularly for surface-air temperature) with the REF distributions remain by mid-century. Given all these considerations, we can then gauge the extent of how these global results translate into regional features of risk through a procedure described in the next section. 


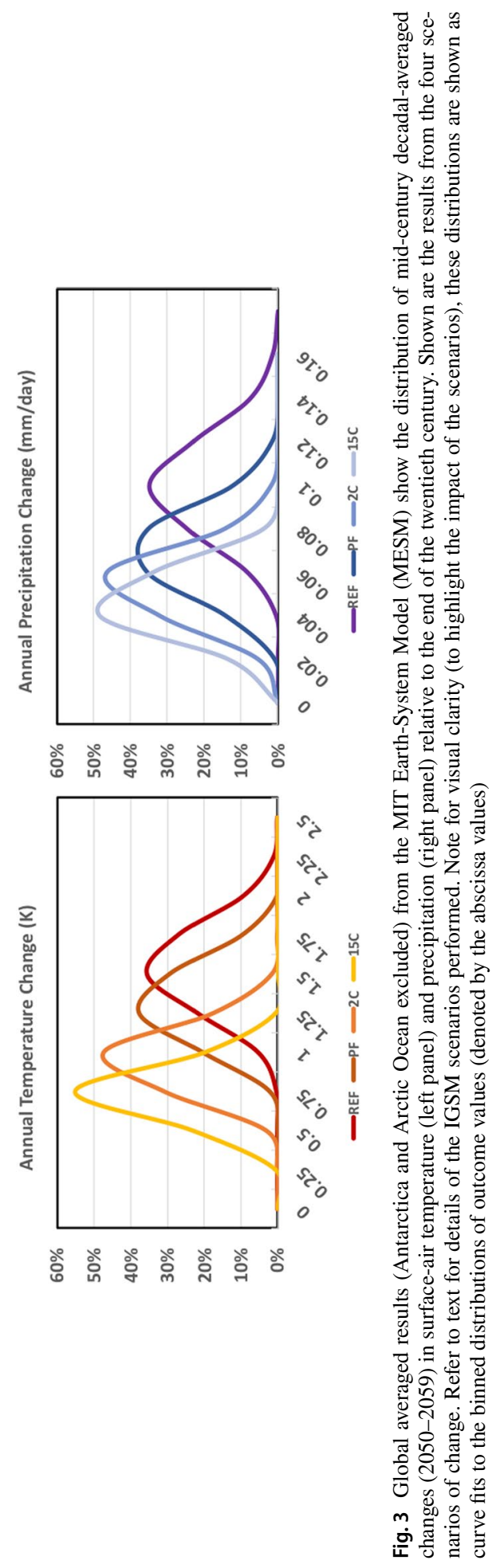




\subsection{Regional climate-change pattern kernels}

Climate information from the IGSM is supplied by the MIT Earth Systems Model (MESM) that is able to provide projections of human-forced change at the zonal level of detail. The most recent version of MESM has been extensively evaluated (Sokolov et al. 2018) and includes diagnoses of key hydro-climatic variables, namely precipitation and surface-air temperature. Its performance against observations at the global and zonal scales is comparable to that of global climate models from Coupled Model Intercomparison Project Phase 5 (CMIP5, Taylor et al. 2012). As previously mentioned, MESM's climate sensitivity is also bounded and sampled across the range of observed estimates (Libardoni et al. 2018). Furthermore, we have also determined that MESM's global hydrologic sensitivity (i.e., the percent change of global precipitation to a unit increase in global temperature) aligns strongly with state-of-the-art climate models (Paltsev et al. 2021). Thus, MESM is an efficient model that can faithfully produce the global- and zonal-scale aspects of plausible climate responses to anthropogenic drivers.

In order to provide regional texture to the MESM simulations, we must expand this information across longitudes using a "pattern scaling" method tailored to the MESM configuration. The use of pattern-scaling methods in climate change scenario assessments and impact studies is extensive and varied (e.g., Santer et al. 1990; Wigley et al. 2000; Mitchell 2003; Frieler et al. 2012; Lopez et al. 2013; and Herger et al. 2015). For our particular application to the MESM framework, the full description and evaluation is provided in Schlosser et al. (2012), and herein we describe the key features of this transformation procedure. In the simplest terms, for any MESM-simulated zonal variable of interest, $V_{y}$, at a given latitude $(y)$ under a human-forced global temperature change $\left(\Delta T_{G}\right)$, we can write a transformation of that variable's value at a given longitude $(x)$ along the latitude band using the following Taylor-expansion-based numerical relationship:

$$
V_{x, y}\left(\Delta T_{G}\right)=\bar{C}_{x, y} V_{y}+\left[\frac{d C_{x, y}}{d T_{G}} \Delta T_{G}\right] V_{y}
$$

where $\bar{C}_{x, y}$ is a climatological-average transformation coefficient, which alters the zonal mean value to a particular value for a longitudinal point along the zonal band. We estimate $\bar{C}_{x, y}$ based on observational data. As discussed in Sect. 2.1, we will focus our attention on changes in near-surface air temperature $\left(T_{a}\right)$ and precipitation. Observational data sources are the same as those used in the prior section that summarized the historical climates for our study region (GPCP and CRU). The projected change in globally averaged temperature, $\Delta T_{G}$, is relative to a reference or climatological period (1980-1999). The derivatives of these transformation coefficients, $\frac{d C_{x, y}}{d T_{G}}$, for any point $(\mathrm{x}, \mathrm{y})$ are discretely estimated from climate model information (for further details, see Schlosser et al. 2012, Sect. 2 methodology discussion of Eq. 4). Therefore, we consider and hereafter refer to the $\frac{d C_{x, y}}{d T_{G}}$ terms as "pattern-change kernels" (PCKs) of regional climate shifts. We construct a set of these PCKs from a selection of the CMIP5 climate models (Table 2), and as a result, this provides the regional basis for the large ensembles to construct distributions of change. The CMIP5 model archive provides a comprehensive set of outputs from climate and Earth-system models that have been developed at institutes across the international scientific community. In some cases, these institutes submitted multiple results that were conducted by their model under a variety of different configurations (e.g., different spatial resolutions and/or various parameterization 
Table 2 List of CMIP5 models used to construct the pattern-scaling kernels of climate change response. Shown are the model acronyms, institute/model name, and the horizontal spatial resolution of the model's output used

\begin{tabular}{lll}
\hline Model acronym & Model/institute & Resolution \\
\hline ACCESS1-3 & Australian Community Climate and Earth-System Simulator & $1.875^{\circ} \times 1.25^{\circ}$ \\
BCC-CSM1-1-m & Beijing Climate Center & $1.125^{\circ} \times 1.125^{\circ}$ \\
BNU-ESM1 & Beijing Normal University & $2.8125^{\circ} \times 2.8125^{\circ}$ \\
CanESM2 & Canadian Earth-System Model & $2.8125^{\circ} \times 2.8125^{\circ}$ \\
CESM1-BGC & Community Earth System Model (NCAR) & $1.25^{\circ} \times 0.9375^{\circ}$ \\
CMCC-CM & Centro Euro-Mediterraneo Cambiamenti Climatici Climate & $0.75^{\circ} \times 0.75^{\circ}$ \\
& Model & \\
CNRM-CM5 & Centre National de Recherches Meteorologiques & $1.40625^{\circ} \times 1.45^{\circ}$ \\
CSIRO-Mk3-6-0 & Commonwealth Scientific and Industrial Research Organization & $1.875^{\circ} \times 1.875^{\circ}$ \\
FGOALS-s2 & Flexible Global Ocean-Atmosphere-Land System & $2.8125^{\circ} \times 1.66^{\circ}$ \\
GFDL-CM3 & Geophysical Fluid Dynamics Laboratory & $2.5^{\circ} \times 2.0^{\circ}$ \\
GISS-E2-R & Goddard Institute for Space Studies & $2.5^{\circ} \times 2.0^{\circ}$ \\
HadGEM2-ES & Hadley Centre Global Environmental Model & $1.875^{\circ} \times 1.25^{\circ}$ \\
INMCM4 & Institute of Numerical Mathematics & $2.0^{\circ} \times 1.5^{\circ}$ \\
IPSL-CM5B-LR & L'institut Pierre-Simon Laplace Coupled Model & $3.75^{\circ} \times 1.875^{\circ}$ \\
MIROC5 & Model for Interdisciplinary Research on Climate & $1.40625^{\circ} \times 1.40625^{\circ}$ \\
MPI-ESM-MR & Max Planck Institute & $2.5 \times 1.25^{\circ}$ \\
MRI-CGCM3 & Meteorological Research Institute & $1.125 \times 1.125^{\circ}$ \\
NorESM1-M & Norwegian Earth System Model & $2.5 \times 1.875^{\circ}$ \\
\hline
\end{tabular}

prescriptions). In constructing this meta-ensemble, we did not incorporate "sibling" model results and instead selected only one set of model results per institute to determine a representative PCK. This was done in order to avoid biasing in the meta-distribution that would result from using "sibling" PCKs (and thereby inappropriately stacking a regional pattern of change). Given the problematic nature of assessing the relative fidelity climate model projections (e.g., Reifen and Toumi 2009), there was no preferential selection to one model result (e.g., the highest spatial resolution) when multiple configurations were available from an institute. This was also done so as to avoid any other possible sources of biasing when deriving these PCKs across all the models/institutes, and to achieve a diverse sampling of outcomes. As a result, the model results from 18 distinct institutes that participated in the CMIP5 exercise were used (see Table 2). As shown in our prior studies, the generation of each of the PCKs was constructed at the native model resolution, and then interpolated to a $2^{\circ} \times 2.5^{\circ}$ common grid, which was commensurate with the coarsest model grid from the CMIP5 model pool. Furthermore, we construct the PCKs using the results from the $1 \%$ transient $\mathrm{CO}_{2}$ simulations. In prior work, we have demonstrated that the PCKs that we estimate for a given climate model are robust across CMIP scenarios (see Schlosser et al. 2012-Tables 1 and 2 for consistency summary). Combined with the 400 members of a MESM ensemble (at a $4^{\circ}$ zonal resolution), we employ (1) to obtain patterns of change results in a meta-ensemble of 7200 members per scenario (described in Sect. 2.2). This 7200-member meta-ensemble we refer to as a "hybrid frequency distribution" (HFD). Each HFD is used as the basis of our risk quantification and represents the range of outcomes that results from the 
global and regional structural uncertainties (from MESM and the PCKs). These will allow us to assess impact of the global policy and climate target on the regional hydroclimatic variables. As a precursory assessment, we summarize the model-mean, consensus, and diversity of the PCKs across the CMIP5 models as well as the corresponding results from the MESM simulations.

\subsubsection{Temperature}

Overall, the CMIP5 model-mean of $\frac{d C_{x, y}}{d T_{\text {Global }}}$ (or PCK) for $T_{a}$ (Fig. 4) exhibits a distinct "colder ocean and warmer land" (COWL) pattern (e.g., Broccoli et al. 1998) across all seasons. This overall pattern is seen for all seasons, but the extent and geographic center of the maxima vary. Although not shown, the MESM scenarios' ensembles produce zonal profiles of warming that are fairly constant across the latitude bands that span this region. As described in the prior section, the effect of this PCK is to then produce an enhanced warming over land as global (and zonal) temperatures rise. This relative warming is at its greatest spatial extent in the spring (SON), and at its weakest during summer (DJF) with commensurate conditions into the fall season (MAM). While the model-mean PCKs suggest that this enhanced warming is consistent across all land areas, a closer inspection of the individual model PCKs (Fig. 5) indicates there are locations where a local buffering effect would be imposed upon the global (and zonal) warming profiles produced. In two particular model cases (for DJF), this opposing relative trend spans almost the entirety of the ESoAfr region for one model and the WSoAfr region for the other. With respect to our

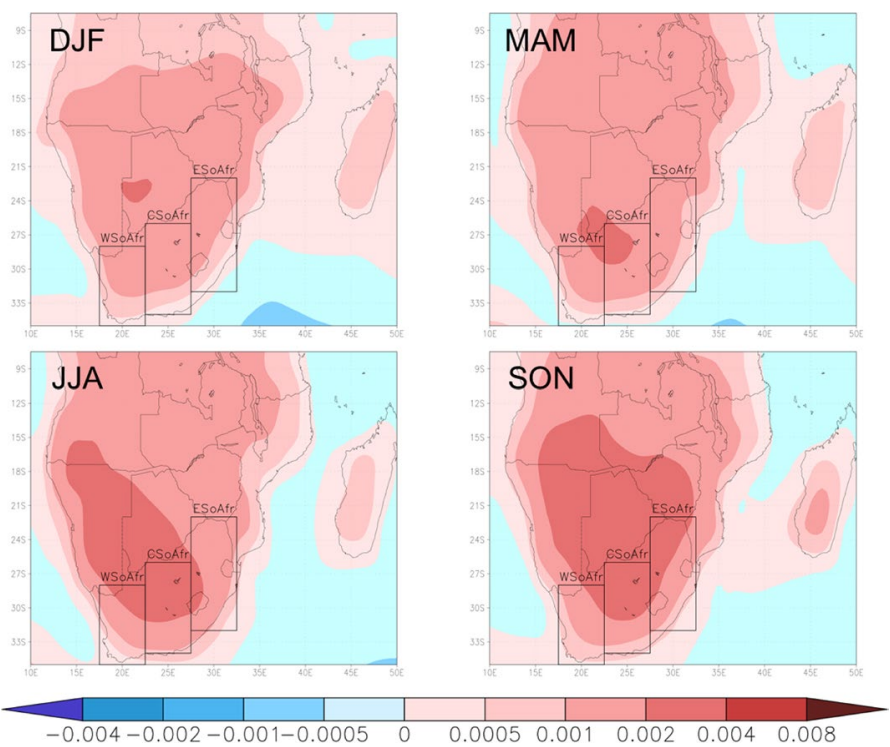

Fig. 4 Maps of the pattern-change kernel (PCK) coefficients, $\mathrm{dC}_{\mathrm{x}, \mathrm{y}} / \mathrm{dT}_{\text {global }}$ (units of $\mathrm{K}^{-1}$ ), over southern Africa for surface-air temperature averaged over the results from the CMIP5 climate models. Shown are the seasonally averaged pattern shifts for December-February (DJF), March-May (MAM), June-August (JJA), and September-November (SON). In each frame, the three regions of focus over South Africa (WSoAfr, CSoAfr, and ESoAfr) are denoted 


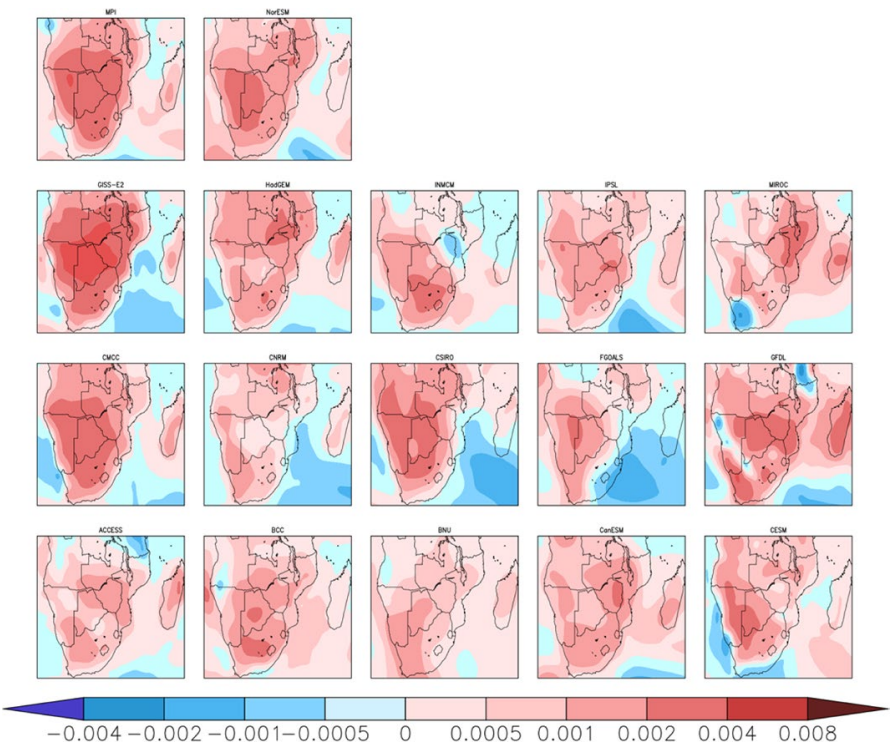

Fig. 5 Maps of the pattern-change kernels (PCKs) coefficients, $\mathrm{dC}_{\mathrm{x}, \mathrm{y}} / \mathrm{dT}_{\text {global }}$ (units of $\mathrm{K}^{-1}$ ), over southern Africa for surface-air temperature. Shown are the results for each model of the CMIP5 collection of the seasonally averaged pattern shifts for December-February (DJF)

regional focus over South Africa, other models show isolated buffering patterns to warming that are confined to a shallow inland extent from a coastline.

\subsubsection{Precipitation}

The model-mean as well as inter-model features of the PCKs for precipitation (Fig. 6) shows a greater degree of heterogeneity (as compared to temperature) across all seasons and regions. However, the most persistent feature is the PCKs imposing a relatively weaker precipitation rate as climate warms across all of the WSoAfr region for all seasons. In contrast, the WSoAfr region exhibits varying degrees of a dipole-like pattern across seasons (except MAM), in which the model-mean PCK would impart a relative enhancement across its southern half and a relative weakening in the northern half of precipitation rates. The CSoAfr region shares features with either ESoAfr or WSoAfr depending on the season. In the cold season (JJA), the model-mean pattern imparts relatively weaker precipitation rates (similar to WSoAfr), and for the remaining seasons its PCK predominantly resembles the landscape of the ESoAfr in sign and/or overall pattern orientation (i.e., north-south oriented gradient). Notwithstanding these common features in the model-mean results, the prominent feature to the precipitation PCKs (particularly in light of the temperature PCKs) lies in the explicit inter-model features (summarized by Figs. 7, 8, 9).

Looking at the PCKs across the individual models (Fig. 7 provides the results for DJF as an example), there are subsets of models that present qualitatively similar largescale orientations of relative increases and decreases - but each model PCK carries with it important, unique features that are commensurate in spatial scale to the South Africa sub-regions of interest. From the remaining pool of CMIP5 models, there are PCKs that indicate a very distinct model response. These considerations raise a question as to the 


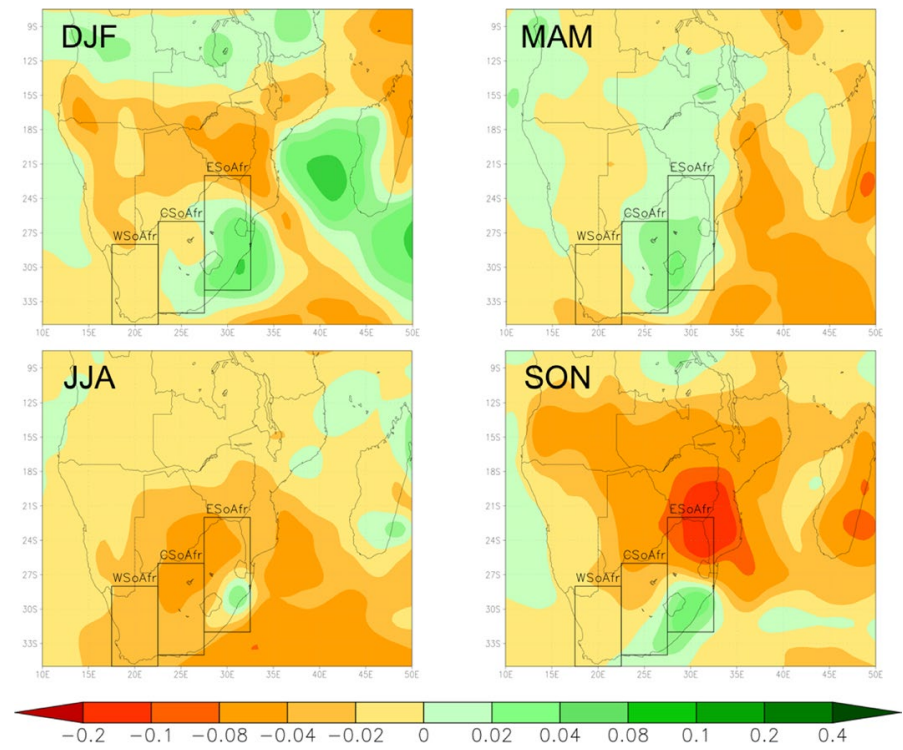

Fig. 6 Maps of southern Africa showing the pattern-change kernel (PCK) coefficients, $\mathrm{dC}_{\mathrm{x}, \mathrm{y}} / \mathrm{dT}_{\text {global }}$ (units of $\mathrm{K}^{-1}$ ), for precipitation averaged over the results from the CMIP5 climate models. Seasonally averaged pattern shifts shown for December-February (DJF), March-May (MAM), June-August (JJA), and September-November (SON). In each frame, the three regions of focus (WSoAfr, CSoAfr, and ESoAfr) are denoted

overall pattern of model "consensus." To assess a landscape of consensus, we first perform a point-wise calculation of the standard deviation across the CMIP5 models' PCK values we obtained on the $2^{\circ} \times 2.5^{\circ}$ common grid resolution (Fig. 8). For all seasons across the South Africa regions, we find that this metric of consensus follows an east-west gradient with the lowest values of inter-model standard deviation confined to the WSoAfr region. The ESoAfr region consistently displays the largest degree of model differences that can be up to an order of magnitude larger than values typically found across the WSoAfr region. The CSoAfr region is typically oriented along a distinct gradient between these contrasting features along its eastern and western flanks. Given this, the consistency in the sign of the PCKs (Fig. 9) is also considered. In alignment with the relatively low inter-model standard deviations, the strongest extent of "consensus" in the sign of precipitation change is located over the WSoAfr region (seen in JJA) with over $75 \%$ of the models in agreement (to the sign of the model-mean). While all the regions show that at least $50 \%$ of the models agree in sign for JJA, in DJF the CSoAfr region as well as the northern portion of ESoAfr shows a lack of sign agreement (i.e., less than $50 \%$ of the models agree in sign to the model-mean value).

Taken altogether within the construct of the HFD framework (summarized by Eq. 1), the presented regional distinctions in PCKs essentially underscore the inherent risk-based nature of climate change and its effect on regional precipitation change. An additional consideration is the contribution of the MESM's zonal-based projections of change, and in particular, their alignment with the landscapes of the PCKs (Figs. 10 and 11 summarize for DJF and JJA, respectively). For the summer season (DJF), the preponderance of MESM's zonal projections (i.e., most if not all the inter-quartile range) produces a decrease in precipitation rates. The only exception is the southern-most latitude of the MESM model 


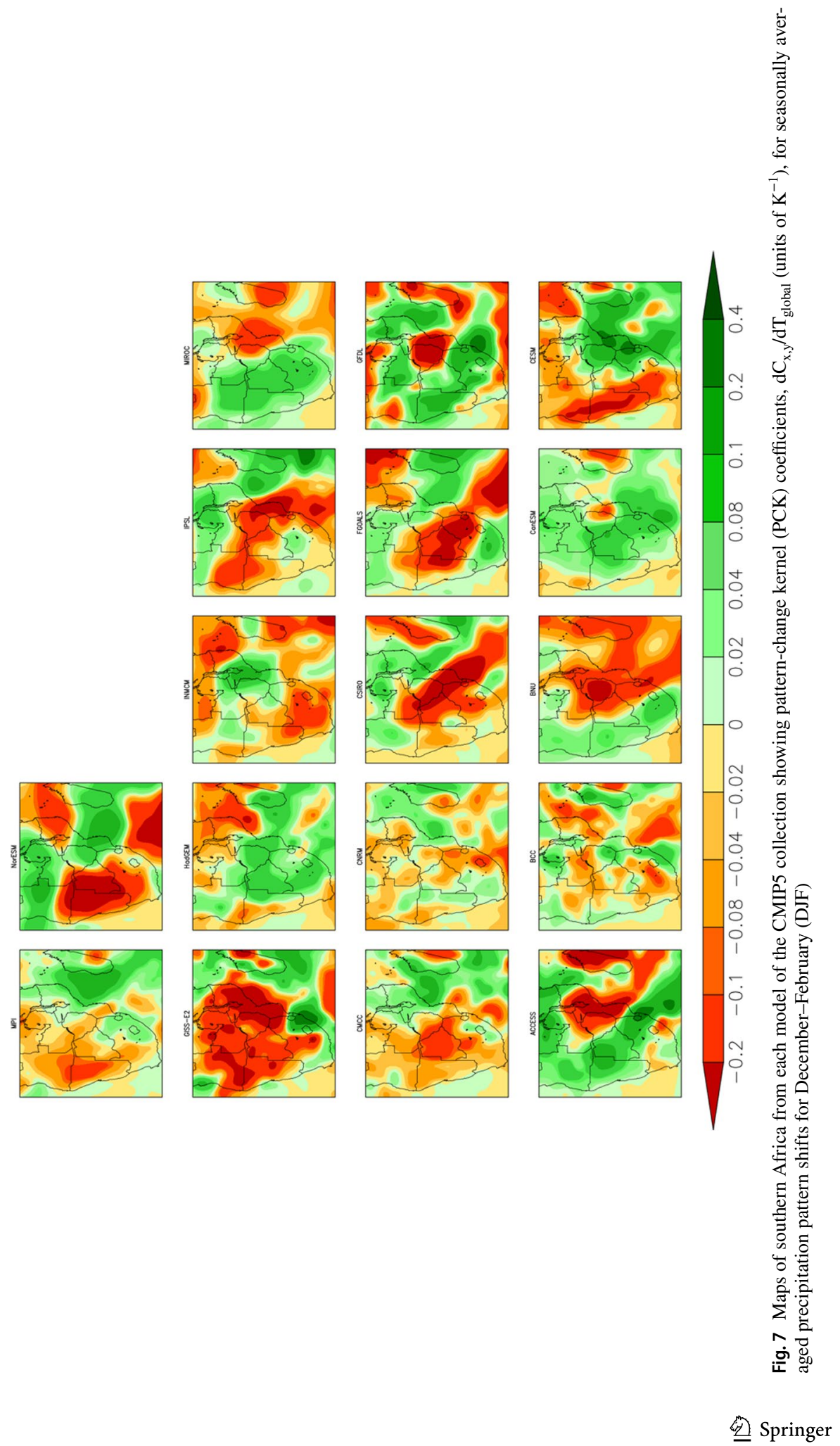



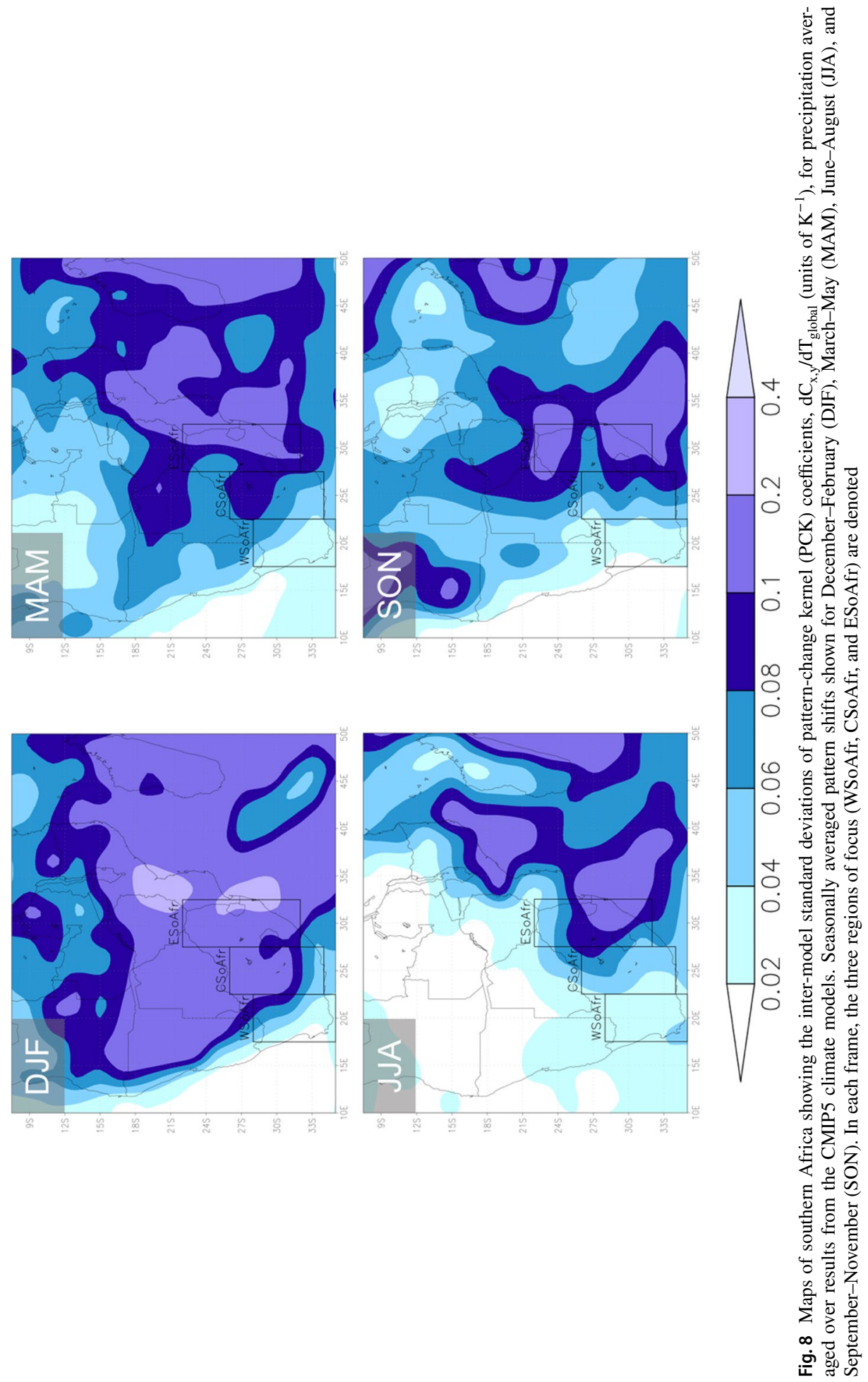


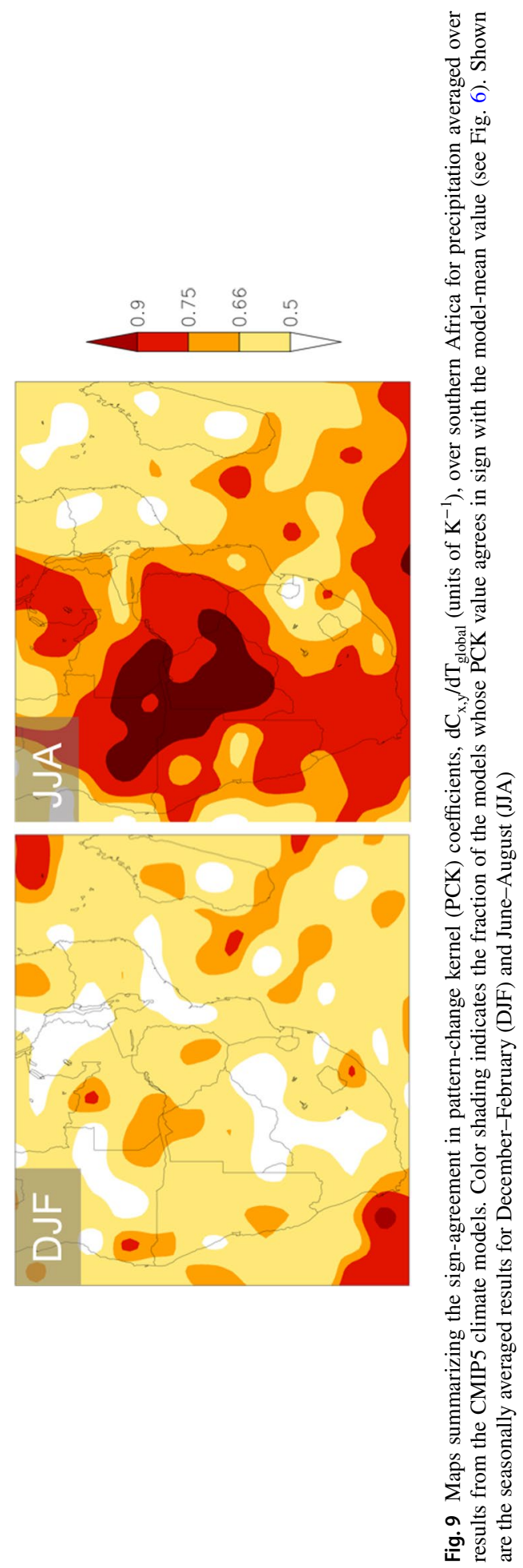




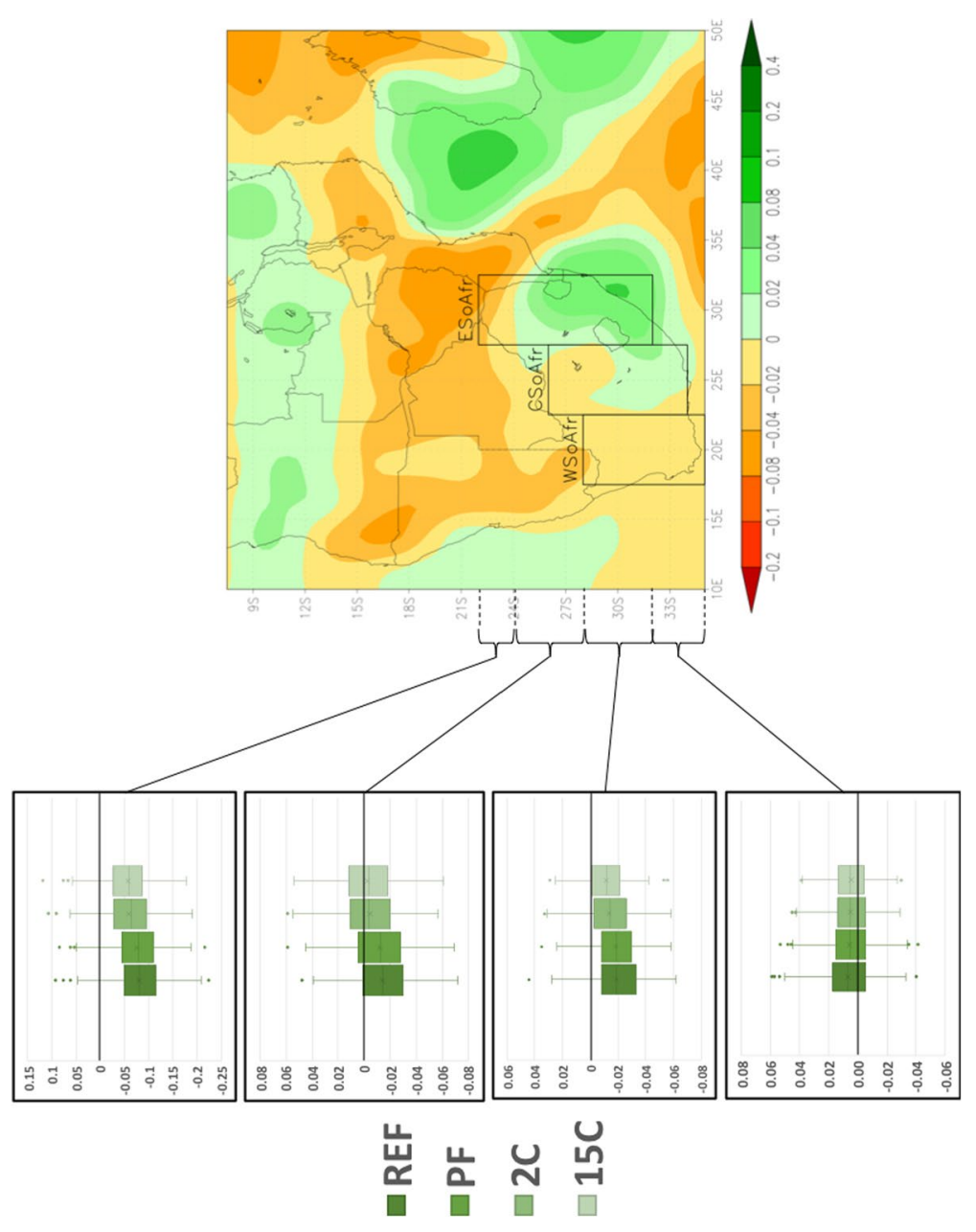

है

ज्ञ

过

胥

过

Ð

范

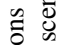

宓

..

为

豆出

is

¿્ّ

$\Xi \Xi$

祗

들

氙

吾是

늘

조

ఫิ

\&

응

己્ّ प

든

을

ญี

잉

อั

(1)

气 ब 氠

ธ్丶

층

อี

है

哭.

현

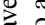

1)

这

으 웅

현 


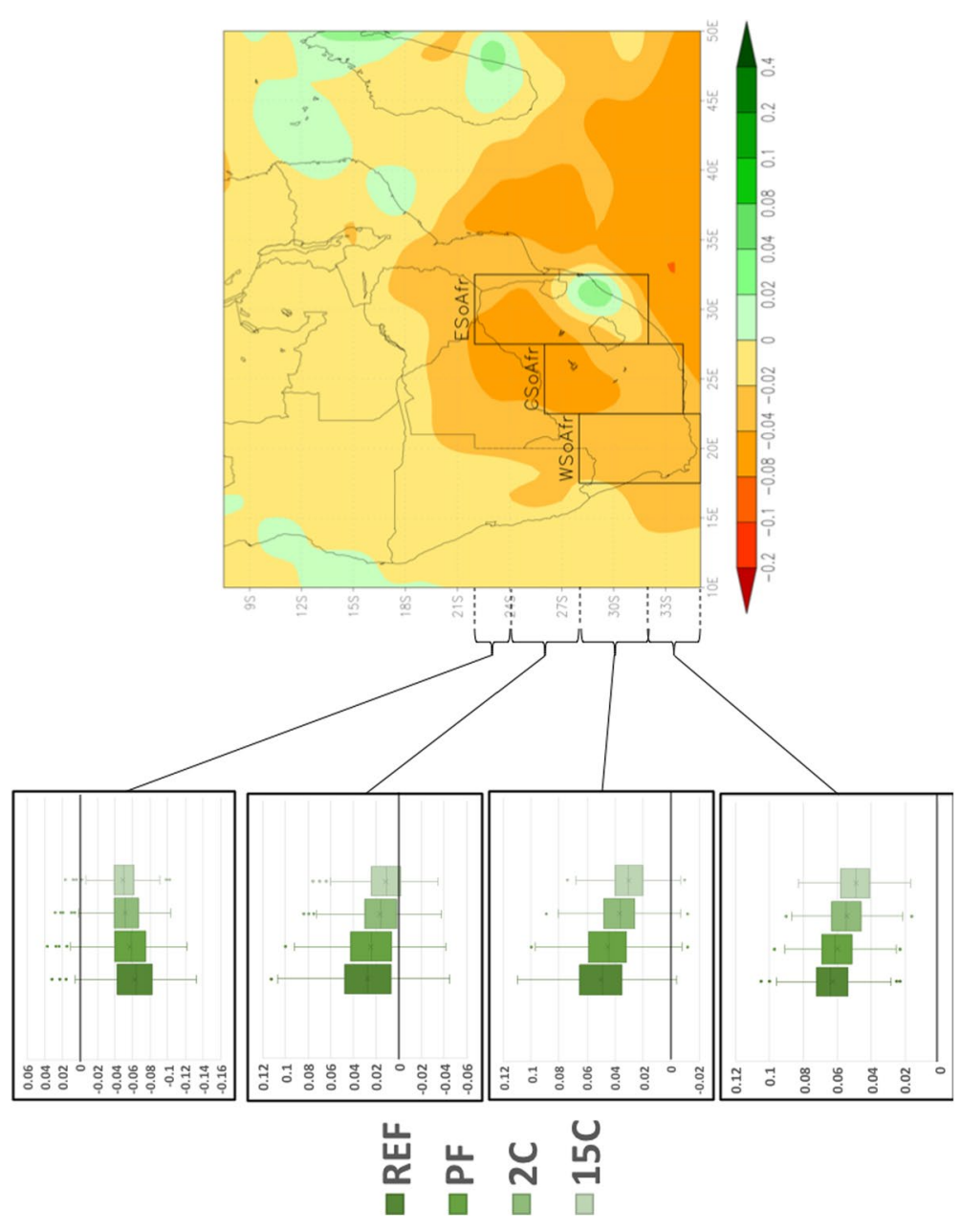

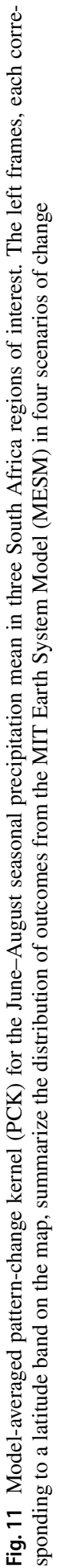


that covers South Africa, yet even for this zonal band the interquartile range spans both increased and decreased precipitations - and will play an important factor into the resultant meta-ensemble outcomes. Conversely, for JJA, the MESM profiles predominantly project increased precipitation rates, with the exception of the northern-most latitudes that intersect with the ESoAfr region. Here, a complex combination exists of predominantly decreased zonal precipitation rates with a model-mean PCK indicating an enhanced reduction in precipitation rate, but with large inter-model scatter and weak sign agreement of PCKs. Furthermore, the preponderance of the zonal trends to one sign of change is minimized and the central tendency of change is decreased by the scenarios of stronger climate targets (i.e., the $2 \mathrm{C}$ and $15 \mathrm{C}$ scenarios). This again underscores the risk-based nature of this assessment framework, and the next section presents a more quantitative inspection of how these compounding effects result in a distribution of outcomes across the regions of interest.

\subsection{Hybrid frequency distributions}

\subsubsection{Mid-century changes}

For all the regions considered and (averaged) through the mid-century, there is a very high likelihood that seasonally averaged surface-air temperatures will warm to a level that is salient relative to historical variations (Fig. 12). As previously discussed

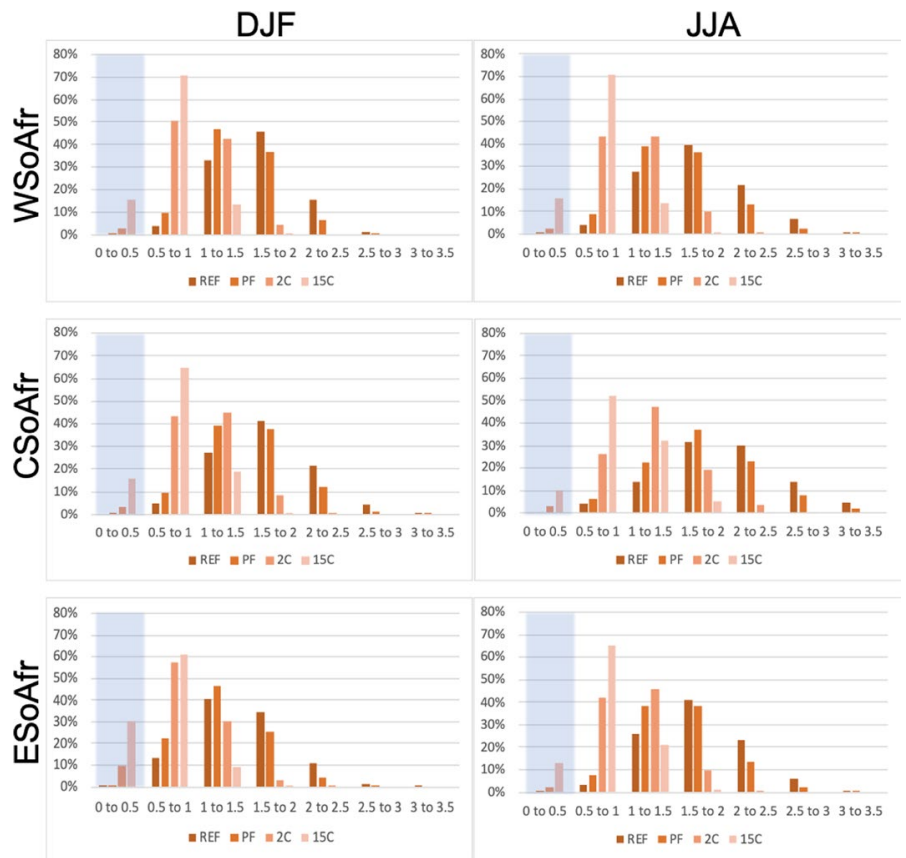

Fig. 12 Hybrid frequency distributions (HFDs) of decadal- and area-averaged surface-air temperature change $\left({ }^{\circ} \mathrm{C}\right.$ ) for 2050-2059 relative to the last decade of the twentieth century in all three sub-regions of South Africa, December-February (DJF) and June-August (JJA). Each panel provides results for all four IGSM scenarios (refer to text for details) 
(Sect. 2.1), the threshold of salience is judged against observed climatological variability (Table 1), and we set a value of 2 standard deviations to the seasonally averaged decadal-mean quantities (blue shaded regions in Fig. 12), at or beyond which any change is regarded as "salient." In the strict sense, this is not an indication of statistical significance but when considering any variable that is aligned with a Gaussian distribution (such as surface-air temperature), the \pm 2 standard deviation range would span $95 \%$ of the total population of values. Therefore, by this measure, a temperature change of this magnitude (and higher) directly associated with anthropogenic emissions lies among the severe-to-extreme climatological population.

In view of this, the results from the HFDs indicate that in all futures considered except the $15 \mathrm{C}$ scenario, over $95 \%$ of the total population of outcomes result in temperature changes above the level of salience (Fig. 12, all panels). Most notably, in all but one of regions and seasons considered (ESoAfr in summer), the REF and PF scenarios show that at least $50 \%$ of their distributions result in temperature changes that are at least triple in magnitude to the salience threshold. These likelihoods are substantially reduced in the $2 \mathrm{C}$ scenario, with most regions and seasons showing at most $10 \%$ of the population remaining (in one case only, CSoAfr in winter, remains at 25\%) within the tripledsalience regime. For the $15 \mathrm{C}$ scenario, the likelihood of these conditions is nearly eliminated (total portion of distribution at or below 5\%). Among the more striking of results is that for the $15 \mathrm{C}$ scenario, the most likely temperature change (with greater than $50 \%$ of all the outcomes for all regions) is just above the level of salience and more closely aligned with historical temperature variations. In addition, at least $10 \%$ of the population of the regional seasonal temperature changes from the $15 \mathrm{C}$ scenario have values that are commensurate to historical variability (i.e., below salience level).

As previously noted (Sect. 2.3.2), the precipitation pattern changes across the CMIP5 models differ in sign and structure both across and within the sub-regions of interest. Therefore, the resultant HFDs will (necessarily) reflect likelihoods of both increased and decreased changes. Similar to precipitation, we prescribe a degree of salience in order to provide a quantitative judgment on the magnitude of change. Additionally, the relative preponderance of "salient" changes toward drier or wetter precipitation rates is also gauged under the recognition that equal chances of a dry or wet future would be the equivalent to a proverbial "coin-toss" as to how one should view the risk of change. Under these considerations, the expected changes in precipitation by midcentury (Fig. 13, "2050s" results) and into the latter half of the twenty-first century (Fig. 14) indicate that there is a greater risk of a "salient" decrease in precipitation for the WSoAfr and CSoAfr regions for both the summer (DJF) and winter seasons (JJA). In the REF scenario by mid-century, the portion of the distribution with decreased DJF precipitation change is about 3 times that of increased precipitation. For JJA precipitation, this relative preponderance is more pronounced with the distributions' portion of precipitation decreases quadruple to that of decreases. For ESoAfr, these distinctions are largely absent at mid-century (Fig. 13, 2050s results) with only a marginally elevated number of outcomes with decreased precipitation (as opposed to increases) during the winter season (JJA), and for the summer the likelihood of decreased or increased precipitation is nearly equal. This feature of the ESoAfr results persists through all of the scenarios considered (not shown). Going into the latter half of the twenty-first century, the likelihood of decreased precipitation change becomes prevalent, yet the largest likelihood of salient decrease has a magnitude of change just slightly larger than historical variability. 


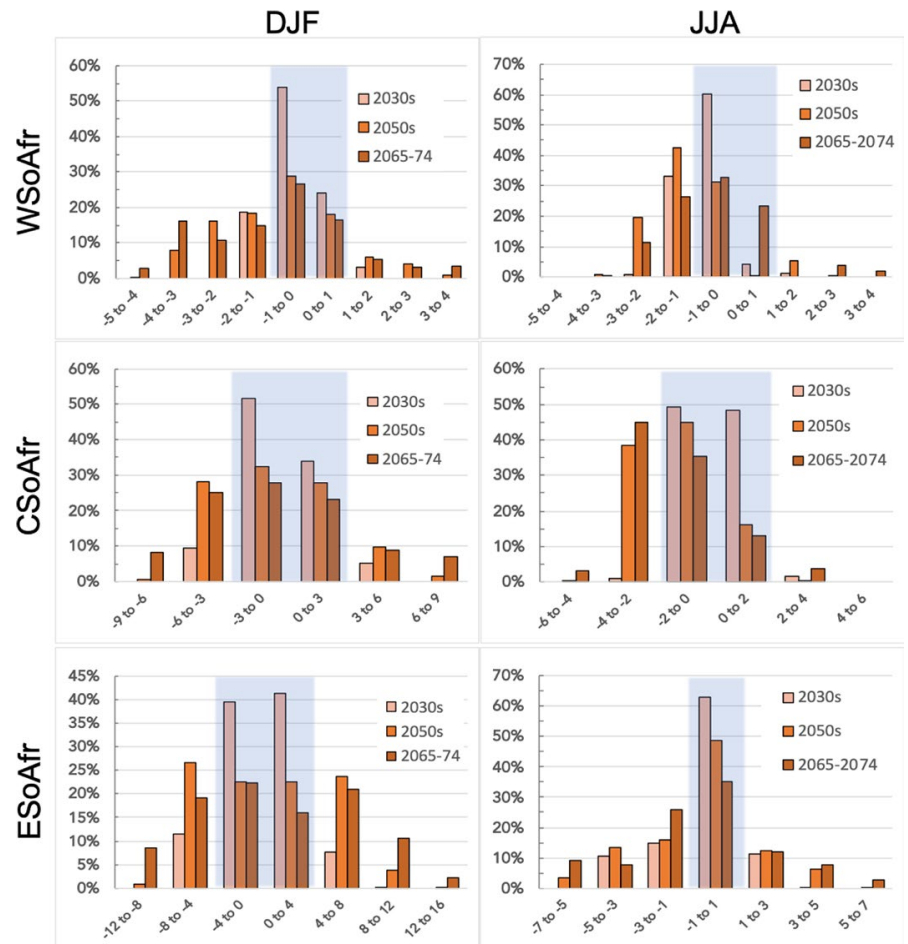

Fig. 13 Reference (REF) scenario HFDs of decadal- and area-averaged precipitation change for 2030-2039, 2050-2059, and 2065-2074 relative to the last decade of the twentieth century in all three sub-regions of South Africa, December-February (DJF) and June-August (JJA). Units in $\mathrm{mm} / \mathrm{decad}$ (decad $=10$ days). Blue-shaded regions denote the bin for which changes in temperature are less than 2 times the standard deviation estimated from observations in the1979-2019 period (see Table 1)

\subsubsection{The evolution of risk and impact of climate targets to abatement}

As shown for the temperature change risks at mid-century (Fig. 12), there is a very clear impact of the more aggressive climate target scenario at reducing (and nearly eliminating) the risk of the very salient (as given by our metrics) temperature changes. Stemming from the diversity in the modeled precipitation response patterns (Sect. 2.3), and that precipitation change is not a positive definite change process as the case for temperature, the impacts of climate-target scenarios reducing risks in precipitation change exhibit different characteristics in their behavior. Whether considering the time-dependent (e.g., Fig. 13) or scenario-dependent (e.g., Figs. 12 and 14) behavior, the HFDs of precipitation-change primarily respond by broadening and/or tightening of the range of outcomes, and as previously noted, in a number of cases the skewness (or relative preponderance toward positive or negative change) is distinctly altered. Consistent to this behavior is the substantial portion of the distribution still contained within the range of changes that are not regarded as "salient" (within the construct of our analyses). This is quite consistent with the variety and diversity of landscapes in the strength and sign of the precipitation PCKs (Sect. 2.3) across and within the three regions of focus. Because of this, there will exist a portion of the distribution that will contain weak PCKs, as well as weak sensitivities and trends-all 

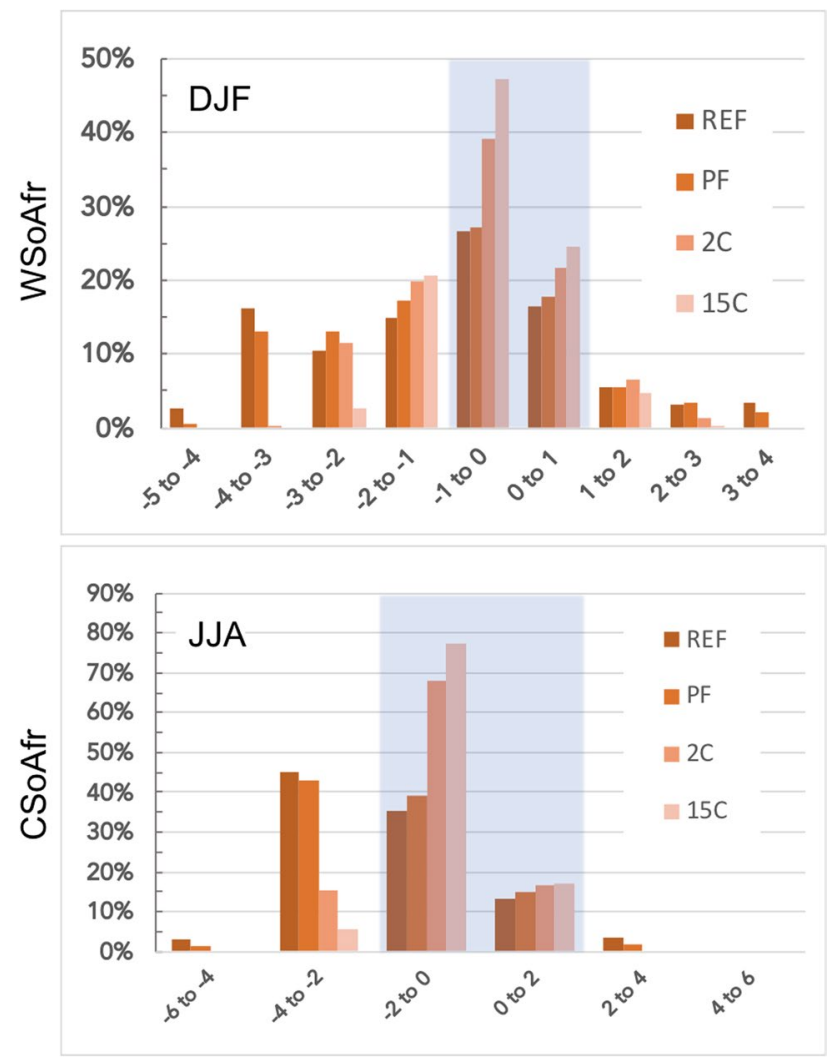

Fig. 14 HFDs of seasonal-, decadal-, and area-averaged precipitation change for 2065-2074 relative to last decade of the twentieth century. Left: December-February (DJF), WSoAfr region. Right: JuneAugust (JJA), CSoAfr region. All four IGSM scenarios shown (refer to text for details). Units in $\mathrm{mm} / \mathrm{decad}$ $($ decad=10 days). Blue-shaded regions denote the bin for which changes in temperature are less than 2 times the standard deviation estimated from observations in the1979-2019 period (see Table 1)

contributing to a fraction of the HFDs with a persistently weaker and more slowly evolving change in the regionally averaged precipitation. Looking into the latter half of the twentyfirst century (Fig. 13 shows results for 2065-2074 seasonal averages), the impact of the more aggressive climate targets to reducing the evolving risks in the REF and PF scenarios is evident. For both the WSoAfr DJF and CSoAfr JJA cases, 45-50\% of their REF and $\mathrm{PF}$ distributions indicate salient decreases in precipitation. This first underscores that even going into the latter half of the twenty-first century, current international commitments put forth by the Paris Agreement do not have any impact to reducing this risk. It is with the more aggressive climate target scenarios $(2 \mathrm{C}$ and $15 \mathrm{C})$ that considerable reductions in risk are seen. Under the $15 \mathrm{C}$ scenario, only $5 \%$ of CSoAfr JJA precipitation change remains outside the salience regime-a nearly tenfold decrease in the likelihood of change from the $\mathrm{REF}$ scenario. The $2 \mathrm{C}$ scenario still results in a sizable decrease down to $15 \%$ (a threefold decrease). For WSoAfr DJF precipitation, the overall impact of the risk in salient change is not as prominent (likelihood is halved); however, both the $2 \mathrm{C}$ and $15 \mathrm{C}$ scenarios eliminate the occurrence of the largest decreases in precipitation. Overall, the impact of the $15 \mathrm{C}$ scenario to reducing risk is most prominently seen when comparing its evolution of risk to 
that seen in the REF scenario (Fig. 15). For all regions and in both summer and winter, the HFDs of precipitation change between the REF scenario in the 2030s compared to the 15C scenario in the 2065-2074 period are nearly identical, and in most cases the likelihood of precipitation changes that are not considered salient are more likely in the $15 \mathrm{C}$ scenario. Thus, this underscores a striking aspect of the $15 \mathrm{C}$ scenarios, in that the overall risks to precipitation change are delayed by about 3 decades.

\section{Summary remarks}

In this study, we have presented risk-based results derived from large ensembles of projected changes in seasonal precipitation and near-surface air temperature over South Africa. The ensemble procedure combines, via a Taylor expansion, regional patterns of emerging climate responses from the CMIP5 climate models with the MIT-IGSM, an intermediate complexity earth-system model coupled to a global economic model that evaluates uncertainty in socio-economic growth, anthropogenic emissions, and global environmental response. Given its computational efficiency, the IGSM can be run for large ensembles (e.g., 400 members in this study) to explore the range of possible global climate responses that result from human and natural forcings. In this study, the numerical experimentation with the IGSM included four scenarios of future climate and socio-economic development in order to span a range of possible global actions to abate greenhouse gas emissions over the coming century. When combined with the CMIP5 regional patterns of climate response

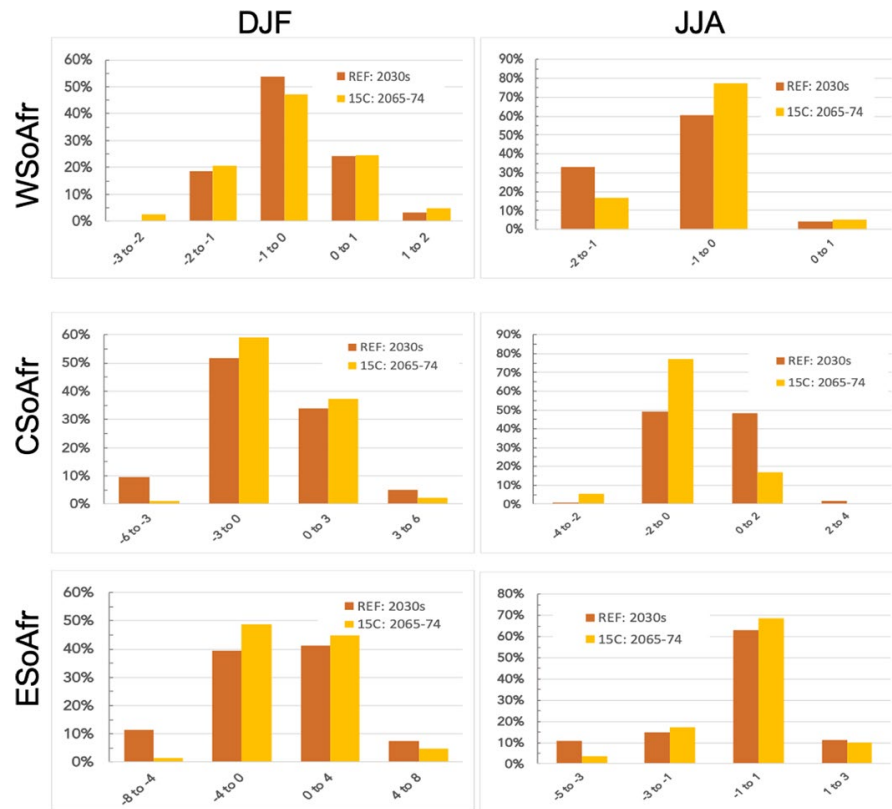

Fig. 15 HFDs of decadal- and area-averaged precipitation change relative to the last decade of the twentieth century in all three sub-regions of South Africa, December-February (DJF) and June-August (JJA). Each panel compares changes in two scenarios and different decadal periods: the reference (REF) scenario for 2030-2039 and the $1.5^{\circ} \mathrm{C}$ (15C) scenario for 2065-2074. Units in $\mathrm{mm} / \mathrm{decad}$ (decad $=10$ days) 
(i.e., pattern-change kernels), the resultant meta-ensembles (1000 s of members) are used to create "hybrid frequency distributions" (HFDs) in order to examine the evolution of climate and the extent to which global actions can abate or avoid changes that are regarded as hazardous.

In terms of the regional patterns of climate model responses to anthropogenic drivers (i.e., emissions), the CMIP5 behavior is largely consistent in the land-sea contrast to their surface-air temperature response patterns. The majority of models impose a relatively stronger warming over land. There are, however, isolated exceptions that primarily stem from the influence of maritime climate, which tend to buffer the warming, and these impacts are seen along coastlines. Precipitation exhibits much more diversity in the CMIP5 patterns of response, and this underscores the necessity of taking a risk-based approach in order to identify the preponderant and salient changes.

We evaluated the HFDs of surface-air temperature and precipitation averaged over three regions across South Africa: western (WSoAfr), central (CSoAfr), and eastern (ESoAfr) South Africa. These regions were drawn to align with some of the key features in the observed climate as well as the characteristics and model consensus of the CMIP5 patterns of response. Across all these regions, we find that by mid-century unless stronger measures are put into force that set stricter climate targets, summer- and winter-averaged temperatures will increase (i.e., over $95 \%$ of the REF and PF scenario member simulations) beyond the current climate's variability. In addition, there is a strong likelihood (nearly $50 \%$ and higher of the REF and PF scenario member simulations) that temperatures will rise considerably higher than the current climate's range of variability (threefold increase over the current climate's two-standard deviation range of variability). The HFD scenarios that consider more aggressive global climate targets (e.g., 2C and 15C scenarios) all but eliminate the risk of these acutely salient temperature increases. For precipitation, the evolving nature of the regional risks exhibits more distinct features across the regions considered. Most notably, for western South Africa, the preponderance of summer precipitation change across the HFD members indicates that there is a considerably greater likelihood that the region will experience reduced precipitation (as opposed to increased) by mid-century even under current global agreements to reduce emissions. However, without these national commitments (under the Paris Agreement) the likelihood of strong decreases in precipitation (i.e., greater than 3 times the current range of variability) is notable (nearly $20 \%$ of the REF ensemble simulations, or a 1-in-5 chance). Given the recent severe drought this region has experienced (e.g., Sousa et al. 2018) and the widespread water-efficiency measures put into action to combat the extreme water shortage, the increasing risk of depleted precipitation that these results imply would indicate that such efficiency measures will become more frequently strained and relied upon. Conversely, across eastern parts of South Africa, the distributions of precipitation change show no clear preponderance toward an increase or decrease through mid-century, and it is only towards the end of the twenty-first century action under the REF scenario are there indications of a greater risk to decreased precipitation.

There is a clear benefit seen within the evolving hydroclimatic risks as a result of strong climate targets, such as limiting the global climate warming to $1.5^{\circ} \mathrm{C}$ by 2100 . In all of the regions considered, we find that the risk of precipitation changes in the $15 \mathrm{C}$ scenario toward the end of this century (2065-2074) is nearly identical to that seen in the REF scenario during the 2030s. The distributions that result from the $15 \mathrm{C}$ scenario toward the end of this century indicate that not all risks of salient changes are removed. Yet, an important aspect of this scenario is that there is a 30-year delay in these risks, relative to the trajectory that is more aligned with the scale of current actions to reduce emissions. This 
30-year delay would likely prove to be invaluable toward any national efforts that would be assessed as necessary to prepare and adapt to these heightened risks.

The results of these large ensembles are part of an ongoing analyses to assess the risks of climate change on agriculture yield and production, and the intent is to apply these to other impact sectors of the economic, energy, and infrastructure systems as warranted.

Funding This work was funded by the IFPRI SA-TIED project, with additional support from the CGIAR Collaborative Research Program on Policies, Institutions, and Markets (PIM) and the CGIAR Collaborative Research Program on Water, Land and Ecosystems (WLE). The authors gratefully acknowledge this as well as additional financial support for this work provided by the MIT Joint Program on the Science and Policy of Global Change through a consortium of industrial sponsors and Federal grants. Development of the IGSM applied in this research was supported by the U.S. Department of Energy, Office of Science (DE-FG02-94ER61937); the U.S. Environmental Protection Agency, EPRI, and other U.S. government agencies and a consortium of 40 industrial and foundation sponsors. For a complete list, see https://globa lchange.mit.edu/sponsors/current.

Data availability Available upon request (via secure file transfer protocol).

Code availability Available via github upon email request to mesm-request@mit.edu.

\section{Declarations}

Conflict of interest The authors declare no competing interests.

Open Access This article is licensed under a Creative Commons Attribution 4.0 International License, which permits use, sharing, adaptation, distribution and reproduction in any medium or format, as long as you give appropriate credit to the original author(s) and the source, provide a link to the Creative Commons licence, and indicate if changes were made. The images or other third party material in this article are included in the article's Creative Commons licence, unless indicated otherwise in a credit line to the material. If material is not included in the article's Creative Commons licence and your intended use is not permitted by statutory regulation or exceeds the permitted use, you will need to obtain permission directly from the copyright holder. To view a copy of this licence, visit http://creativecommons.org/licenses/by/4.0/.

\section{References}

Adler RF, Sapiano M, Huffman GJ, Wang J, Gu G, Bolvin D, Chiu L, Schneider U, Becker A, Nelkin E, Xie P, Ferraro R, Shin DB (2018) The Global Precipitation Climatology Project (GPCP) monthly analysis (new Version 2.3) and a review of 2017 Global Precipitation. Atmosphere 9(4):138. https://doi.org/10. 3390/atmos9040138

Arndt C, Chinowsky P, Fant C et al (2019) Climate change and developing country growth: the cases of Malawi, Mozambique, and Zambia. Clim Change 154:335-349. https://doi.org/10.1007/ s10584-019-02428-3

Broccoli AJ, Lau N-C, Nath MJ (1998) The cold ocean-warm land pattern: model simulation and relevance to climate change detection. J Climate 11:2743-2763

Chen, Y.-H.H., S. Paltsev, J.M. Reilly, J.F. Morris and M.H. Babiker (2016) Long-term economic modeling for climate change assessment. Economic Modelling, 52(Part B): 867-883. (http://www.sciencedirect. com/science/article/pii/S0264999315003193)

Crétat J, Pohl B, Richard Y, Drobinski P (2012) Uncertainties in simulating regional climate of Southern Africa: sensitivity to physical parameterizations using WRF. Clim Dyn 38(3-4):613-634

Fant C, Gebretsadik Y, McCluskey A, Strzepek K (2015) An uncertainty approach to assessment of climate change impacts on the Zambezi River Basin. Clim Chang 130:35-48

Frieler K, Meinshausen M, Mengel M, Braun N, Hare W (2012) A scaling approach to probabilistic assessment of regional climate change. J Clim 25(9):3117-3144. https://doi.org/10.1175/JCLI-D-11-00199.1 
Herger N, Sanderson BM, Knutti R (2015) Improved pattern scaling approaches for the use in climate impact studies. Geophys Res Lett. https://doi.org/10.1002/2015GL063569

Huffman GJ, Adler RF, Bolvin DT, Gu G (2009) Improving the global precipitation record: GPCP Version 2.1. Geophys Res Let 36:1-5

Jones PD, New M, Parker DE, Martin S, Rigor IG (1999) Surface air temperature and its variations over the last 150 years. Rev Geophys 37:173-199

Lennard C, Nikulin G, Dosio A and Moufouma-Okia W (2018) On the need for regional climate information over Africa under varying levels of global warming. Environ Res Lett. https://doi.org/10.1088/ 1748-9326/aab2b4

Libardoni, A.G., C.E. Forest, A.P. Sokolov and E. Monier (2018): Estimates of climate system properties incorporating recent climate change. Advances in Statistical Climatology, Meteorology and Oceanography, 4(1/2),19-36 (10.5194/ascmo-4-19-2018) (https://www.adv-stat-clim-meteorol-oceanogr.net/4/ 19/2018/)

Lopez A, Suckling EB, Smith LA (2013) Robustness of pattern scaled climate change scenarios for adaptation decision support. Clim Change 122(4):555-566. https://doi.org/10.1007/s10584-013-1022-y

Mitchell TD (2003) Pattern scaling — an examination of the accuracy of the technique for describing future climates. Clim Change 60(3):217-242

Niang I, Ruppel OC, Abdrabo MA, Essel A, Lennard C, Padgham J, Urquhart P (2014) Africa. In: Barros VR, Field CB, Dokken DJ, Mastrandrea MD, Mach KJ, Bilir TE, Chatterjee M, Ebi KL, Estrada YO, Genova RC, Girma B, Kissel ES, Levy AN, MacCracken S, Mastrandrea PR, White LL (eds) Climate change 2014: impacts, adaptation, and vulnerability. part b: regional aspects. Contribution of working group ii to the fifth assessment report of the intergovernmental panel on climate change. Cambridge University Press, Cambridge and New York, pp 1199-1265

Osborn TJ, Jones PD (2014) The CRUTEM4 land-surface air temperature data set: construction, previous versions and dissemination via Google Earth. Earth Syst Sci Data 6:61-68. https://doi.org/10.5194/ essd-6-61-2014

Paltsev S, Schlosser CA, Chen Y-H, Gao X, Gurgel A, Jacoby H, Morris J, Prinn R, Sokolov A, Strzepek K (2021) Charting the earth's future energy, managed resources, climate, and policy prospects - 2021 global change outlook. MIT Joint Program on the Science and Policy of Global Change. https://globa lchange.mit.edu/sites/default/files/newsletters/files/2021-JP-Outlook.pdf

Reilly J, Chen Y-H, Sokolov A, Gao X, Schlosser A, Morris J, Monier E, Paltsev S (2018) Food, water, energy, climate outlook, 2018. MIT Joint Program on the Science and Policy of Global Change. https:// globalchange.mit.edu/outlook2018

Reifen C, Toumi R (2009) Climate projections: past performance no guarantee of future skill? Geophys Res Lett 36. https://doi.org/10.1029/2009GL038082

Santer BD, Wigley TML, Schlesinger ME, Mitchell JFB (1990) Developing climate scenarios from equilibrium GCM results. Tech Rep. Max-Planck-Institut für Meteorologie, Hamburg

Schlosser CA, Gao X, Strzepek K, Sokolov A, Forest CE, Awadalla S, Farmer W (2012) Quantifying the likelihood of regional climate change: a hybridized approach. J Clim 26(10):3394-3414. https://doi. org/10.1175/JCLI-D-11-00730.1

Schlosser CA, Strzepek K (2015) Regional climate change of the greater Zambezi River basin: a hybrid assessment. Clim Change 130:9-19

Sokolov A, Kicklighter D, Schlosser A, Wang C, Monier E, Brown-Steiner B et al (2018) Description and Evaluation of the MIT Earth System Model (MESM). J Adv Model Earth Syst 10:1759-1789. https:// doi.org/10.1002/2018MS001277

Sousa PM, Blamey R, Reason CJC, Ramos AM, Trigo RM (2018) The 'Day Zero' Cape Town drought and the poleward migration of moisture corridors. Environ Res Lett 13(12):124025. https://doi.org/10. 1088/1748-9326/aaebc7

Taylor KE, Stouffer RJ, Meehl GA (2012) An overview of CMIP5 and the experiment design. Bull Amer Meteor Soc 93:485-498. https://doi.org/10.1175/BAMS-D-11-00094.1

Thomas T et al (2020) Climate change risks to crop yields over southern Africa (forthcoming paper)

Wigley TML, Raper SCB, Smith S, Hulme M (2000) The MAGICC/SCENGEN climate scenario generator: version 2.4: technical manual. CRU, UEA, Norwich

Publisher's note Springer Nature remains neutral with regard to jurisdictional claims in published maps and institutional affiliations. 